\title{
Environmental Monitoring Systems: Review and Future Development
}

\author{
Ivan Šećerov ${ }^{*}$, Dragan Dolinaj ${ }^{1}$, Dragoslav Pavićn ${ }^{1}$, Dragan Miloševići ${ }^{1}$, Stevan Savić1, \\ Srđan Popov² ${ }^{2}$ Žarko Živanov
}

${ }^{1}$ Faculty of Sciences, University of Novi Sad, Climatology and Hydrology Research Centre, Novi Sad, Serbia

${ }^{2}$ Faculty of Technical Sciences, University of Novi Sad, Novi Sad, Serbia

Email: ^ivan.secerov@dgt.uns.ac.rs

How to cite this paper: Šećerov, I., Dolinaj, D., Pavić, D., Milošević, D., Savić, S., Popov, S. and Živanov, Ž. (2019) Environmental Monitoring Systems: Review and Future Development. Wireless Engineering and Technology, 10, 1-18.

https://doi.org/10.4236/wet.2019.101001

Received: October 15, 2018

Accepted: December 17, 2018

Published: December 20, 2018

Copyright () 2019 by authors and Scientific Research Publishing Inc. This work is licensed under the Creative Commons Attribution International License (CC BY 4.0).

http://creativecommons.org/licenses/by/4.0/

\begin{abstract}
Monitoring and recording large time series of data and making them available for studying-are the key roles of environmental monitoring systems. This study produce review of three different measurement monitoring systems (NSUNET, WAHASTRAT and MERIEXWA) with same design, which were placed during different time frame in the Northern Serbia (Vojvodina Province). Each of three monitoring systems has different demands and requirements which were addressed accordingly in their design. Power supply conditions for two systems are primary cells and solar panels, while NSUNET has constant power supply only during nighttime. Data is transmitted in MERIEXWA using binary protocol, WAHASTRAT using http, while NSUNET sends data over ftp. Same topology is used in all systems-each node sends data directly to the central location (in case of NSUNET two locations are provided for backup purposes). NSUNET system sends data using specific structure and stores them as plain text files. It also has different approach for time synchronization and monitoring issues. The main result of this study is to present how to create system that provides good quality and unchanged data from monitoring sensor to the end user while maintaining whole data structure transmission costs low. Furthermore, data collected from NSUNET were used in order to assess the influence of urbanization on regional climate modification, which leads to the creation of urban climate. Propositions for new system development combining best from all three systems are discussed.
\end{abstract}

\section{Keywords}

Monitoring Networks, Data Acquisition, Data Logger, IoT, Wireless Sensor Networks 


\section{Introduction}

Increasing tendencies for technological development and its impact on surrounding environment, requires better understanding of relationship between elements within it. Short and long turn modifications on environment caused by such changes must be recorded before any analyzing process could be performed. Monitoring and recording large time series of data and making them available for studying - are the key roles of environmental monitoring systems. Being able to store unchanged and reliable information of monitored parameters poses great challenge which must be solved.

Real time data collecting in different environments brings new perspective in science analysis. Whether such data are used to understand better living environment or to predict and produce warning of potential hazard occurrence, different solutions are developed. Studies are made about aspects of environment monitoring systems [1]. Whenever there are remote locations involved, different radio technologies are used for data transmission such as gsm and wirelesses standards. Usually monitoring locations does not have constant power supply which could be used for sensor nodes. In such cases or in case of extra reliability, battery is placed as primary or backup power supply. Radio devices such as gsm modem or wi-fi radio adapter can have different impact on power consumption [2]. Efforts are made to lower the transmission costs and battery usage using technologies such as IEEE 802.15.4 and ZigBee protocol stack [3] [4]. Monitoring environment can require specific sensor placement and communication demands. Recent studies present different topologies used in wireless sensor network such as bus, tree, star, ring, mesh, circular and grid [5]. When data are successfully collected and processed, information provided from sensors environment monitoring systems can be used in different fields, for example, to alert wildfire [6], or to detect air pollution [3]. It can provide in-situ atmospheric data with higher spatial and temporal density [7], monitor $\mathrm{CO}_{2}$ using non-dispersive infrared sensor [6] or water quality of surface freshwaters [9]. Its usage is not limited only on areas above ground level. Systems are used for monitoring of coal mine [10], and aquatic applications, such as environmental monitoring, undersea exploration, disaster prevention, and tactical surveillance [11] and much more. Deploying hardware controlled by specially designed software whose role is to automate data acquisition, helps to understand better environment around us. Low cost data loggers solutions are increasingly used for different fields of data acquisitions [12]. With numerous benefits of automated measurements, data are collected continuously throughout the practice with minimal human intervention [13]. Different solutions integrate wide range of hardware, from propriety to open source micro-controllers such as Arduino [14] [15]. Real-time data collection has important role in various fields such as weather information collection, hydrology analyzes, post disaster assessment [16] and others.

This study presents overview of different solutions developed under three Instrument for Pre-Accession Assistance (IPA) cross-border projects (MERIEXWA, 
WAHASTRAT and URBAN-PATH) used for wide range of measurements within different environment. The main goals are: 1) to present disadvantages of closed and proprietary systems with raw data transfer and data storage; 2) to present advantages of open systems, such as NSUNET, that obtains reliable and unchanged data, from the moment it is measured until the moment it is received by the end user; and 3) monitoring system which is proposed in this study, could be adequate for low-maintenance, since maintenance is generally the problem for University and other scientific Institutions, because of the shortage of financial sources. Hence, this study gives critical overview of achievements as well as the flaws of presented solutions together with suggestion how to improve them in future developments.

\section{Location of Research Area and Monitoring Networks}

The focus of this research is Vojvodina Province (northern part of Serbia) (Figure 1), the area of about $20.000 \mathrm{~km}^{2}$ and about 2 mil. of population. The research area is located on the southern part of the Great Carpathian/Hungarian Plain. The investigated area is plain, on Holocene sediments with a gentle relief, so generally, the climate is free from orographic effects. According to Köppen-Geiger climate classification [17], the region of Vojvodina is categorized as Cf climate (temperate warm climate with a rather uniform annual distribution of precipitation).

WAHASTRAT and MERIEXWA (Figure 1) wireless sensor networks are located to the north around Subotica and in the central part of Vojvodina, around Novi Sad city, respectively (Figure 1). NSUNET wireless sensor network is located in Novi Sad urban area and its hinterland (Figure 1), as the second largest city in the Republic of Serbia, with $102 \mathrm{~km}^{2}$ built-up area and population of 330,000 (data from 2017). The built-up area is on relatively gentle relief between 80 and $86 \mathrm{~m}$, and the southeast outskirts of the city are on a higher altitude, i.e., up to 130. This southeast built-up area is settled on the edge of the northern slope of the low mountain Fruška Gora (highest peak $539 \mathrm{~m}$ ) and separated from most built-up urban area by Danube River (river width from 260 to $680 \mathrm{~m}$ ). Through the northern portion of the city passes the narrow Danube-Tisza-Danube Canal between industrial and residential zones.

\section{Results of Installed Monitoring Networks}

\subsection{MERIEXWA-Network for Monitoring Inland Excess Water}

Inland excess water represents serious threat to agricultural sector [20], houses can become temporarily uninhabitable and roads inaccessible [21]. Depending on the size and location of the affected area, extend of damage could reach high values. Monitoring and possibility to predict its further development represents formidable challenge. Wireless sensor network developed for monitoring of inland excess water in northern part of Vojvodina consists of 25 wells. Monitoring 


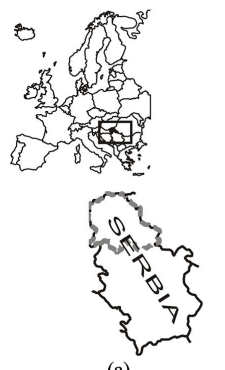

(a)

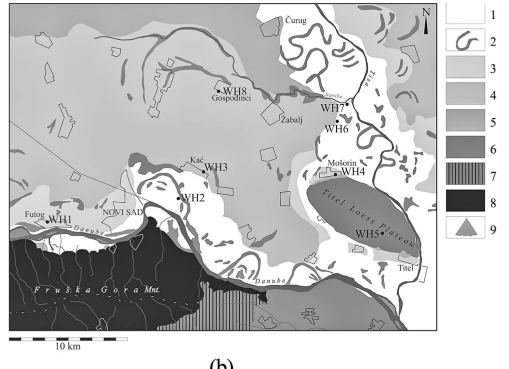

(b)

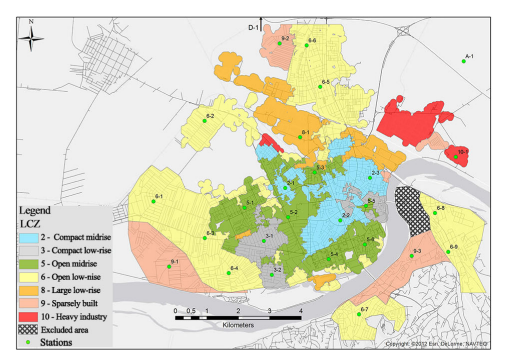

(c)

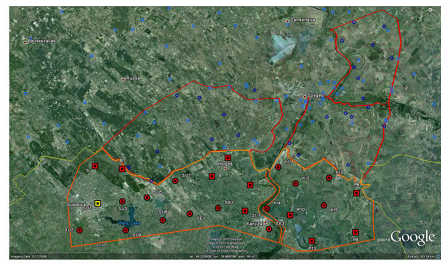

(d)

Figure 1. Location of (a) Vojvodina; (b) WAHASTRAT stations [18]; (c) NSUNET stations [19]; (d) MERIEXWA stations (circles represent already present wells which are equipped with MERIEXWA stations; squares represent wells that are drilled specially for placement of MERIEXWA stations).

system nodes are placed on the top of the each well [22]. Guideline for system design was to monitor changes over long period of time which would allow gathered data to be used as input for hydrodynamic models [22].

The level of inland water is measured using acoustic signal transmitted from KPEG-272 buzzer. Because wells are designed with pipes consisted of polyvinyl chloride (pvc), there were significant reflections from pipe joints. Inland water measurements are done using frequencies of around $4 \mathrm{kHz}$ which made reflections almost insignificant [22]. Microphone ABM-713 is used as receiver. Monitoring area has good mobile Internet providers coverage, so gsm technologies are used for data transport.

Since there are no power supplies around wells, nodes are equipped with $\mathrm{Li}$ thium Thionyl Chloride ( $\mathrm{Li}-\mathrm{SOCl}$ ) battery pack which has property to work on very low temperatures (up to $-40^{\circ} \mathrm{C}$ ) with low self-discharge rate. Output battery voltage is $3.6 \mathrm{~V}$ and capacity is $19 \mathrm{Ah}$, which have been adequate to power the MERIEXWA system for 2 years [23]. After that period system would stop to produce measurements unless new batteries are installed.

Each node collects measurement data for defined period. After modem is successfully turned on, recording of the current date and time is made, which is followed by detection of the current battery voltage. Data are sent using raw structure. First few bytes represent "header" which defines overall length of settings and measurement data. Stations configuration settings are deployed next which are followed by measured data. Upon successful transmission, new configurations sent from server are received. When settings are stored, session is complete and modem is turned off so that battery power could be preserved. Data structure used between stations and the server are defined as settings and measurement data.

Each station has its unique "deviceId", which is used to distinguish received data on server. Ip socket on which server application listens is defined using ip address ("serverIp") and tcp port ("tcpPort"), gsm network provider settings, measurement period and station wake up time are defined using their respected values.

Overall size of data used for settings definition is around 14 bytes. Measure- 
ment data are defined as: date and time, battery voltage, measurement mode, internal and external temperature (temperatures measured inside and outside stations case), response time (in samples) and response maximum. Overall size of data used for measurement definition is around 16 bytes. Due to the fact that water levels cannot significantly change in smaller periods of time, measurements are performed once per day.

Entire MERIEXWA system has centralized design [24]. Each monitoring node sends data to the single server. Server side application is developed as non-modular and it is written in java language which allows it to work on different platforms without the need for major modifications. Data communication between stations and server side is performed using binary protocol developed for MERIEXWA system.

After station is successfully connected, basic authentication is performed only to determine which station is sending data. Data that is gathered after last successful transmission is sent. Received data are converted into structure acceptable by sqlite database. Guidelines for selecting sqlite as database used in MERIEXWA system was its simplicity and low impact on server resources. Transmission is ended when station has no more data to send.

Measured data stored in database is accessed using small web application developed in java language also. Communication between server side and client is done using http. Basic function of application is to output data in format which is suitable for further data analyze. Some basic monitoring capabilities are implemented mainly to provide information about the status of stations (Figure 2).

Field "Not sent in last 10 days" is used to inform whether stations are operational or not. If value is set to "No", station is operational. Value "Yes" suggests that station didn't send any data for the defined period. Due to the fact that for the MERIEXWA project required transmission period is seven days, such value is used in the system.

Cron jobs (time-based job scheduler in Unix-like computer operating systems) represent automated tasks used to analyze entire MERIEXWA system work. Most important task is daily report, run at the end of each day. Gathered information are sent to the technicians using email solely to alert if there are errors in acoustic signal or if there are no data sent in last then days. Second cron job is defined as Watchdog task, which is run couple of times per day, and is used to analyze received data. If data are near defined thresholds, special form of daily report is sent via email also (Figure 3 ).

\subsection{WAHASTRAT-Network for Monitoring Meteorological Val- ues}

Water shortage and drought, as the most important hydro-climatic hazards, cause significant damages in case of most continents [18]. In order to better understand such conditions, WAHASTRAT system was developed under IPA cross-border project which goal was to monitor water conditions in Bačka re- 
gion located in southern part of the Great Plain of Carpathian (Pannonian) basin. WAHASTRAT consists of 8 remote stations equipped with Decagon EC-5 Volumetric Water Content sensor which is used to determine volumetric water content (vwc) by measuring the dielectric constant of the media using capacitance and frequency domain technology. Together with integrated Davis sensors, soil moisture, temperature and wind velocity are collected by each measurement.

Each station is solar-powered and supplied with a maintenance-free, non-spillable battery providing at least 30 days of autonomy, when there is little or no sunshine.

Data are sent using gsm modem through http and are defined as raw data structure. When wake up time is reached, station changes from sleep to active mode. After successful connection to the server is established, configuration is received. If configuration is valid, actual transmission of measured data is performed. In case of network related failures, data are stored in the station internal memory and will be re-transmitted during next session.

Server side application validates data, format it and store in Microsoft sql database server.

System time used by the station is based on local time zone. Whenever data are sent to the server, measured time is being checked against servers current time. If there is gap due to daylight savings change, measured time is corrected.

Web based application is used to produce statistics about system work and export data to Microsoft Excel file (Figure 4).

\begin{tabular}{|c|c|c|c|c|c|c|c|c|c|c|c|c|}
\hline ID & Location & $\begin{array}{l}\text { Measured } \\
\text { operator }\end{array}$ & $\begin{array}{l}\text { Data transmission } \\
\text { period }\end{array}$ & Acc counter & Alarm hours & Alarm minutes & Attenuation & & Changes counter & Last data arrival & Action & \\
\hline 0 & nulti & 1 & 1 & 0 & 1 & 1 & 1 & 680 & -34 & 2013-11-22 19:21:24 & Change & Show \\
\hline 1 & su1 & 1 & 7 & 0 & 15 & 1 & 215 & 1300 & -1 & 2014-02-08 15:06:31 & Change & Show \\
\hline 2 & K13 & 0 & 7 & 32 & 15 & 2 & 150 & 1070 & -2 & 2014-02-07 11:55:18 & Change & Show \\
\hline 3 & su5 & 1 & 7 & 32 & 15 & 3 & 200 & 970 & 0 & 2014-02-07 15:07:18 & Change & Show \\
\hline 4 & SE3 & 1 & 7 & 32 & 15 & 4 & 100 & 800 & 0 & 2014-02-05 15:08:02 & Change & Show \\
\hline 5 & P14 & 1 & 7 & 32 & 15 & 5 & 180 & 690 & 0 & 2014-02-04 15:09:16 & Change & Show \\
\hline 6 & 8SE & 1 & 7 & 32 & 15 & 6 & 210 & 850 & 0 & 2014-02-05 15:11:03 & Change & Show \\
\hline 7 & su3 & 1 & 7 & 32 & 15 & 7 & 150 & 660 & -1 & 2014-02-05 15:13:16 & Change & Show \\
\hline 8 & K14 & 1 & 7 & 32 & 15 & 8 & 200 & 1190 & -4 & 2014-02-05 16:29:54 & Change & Show \\
\hline 9 & P8 & 1 & 7 & 1 & 15 & 9 & 180 & 1000 & -3 & 2014-02-04 23:37:42 & Change & show \\
\hline 10 & $31 \mathrm{~T}$ & 1 & 7 & 32 & 15 & 10 & 200 & 300 & -1 & $2014-02-05$ 15:16:30 & Change & Show \\
\hline
\end{tabular}

Figure 2. Web portal used for monitoring of MERIEXWA system.

\begin{tabular}{|c|c|c|c|c|}
\hline & Sensor & Max $>2450$ & \begin{tabular}{|c|} 
Samples \\
0
\end{tabular} & \begin{tabular}{|c|} 
Not sent within last \\
10 days
\end{tabular} \\
\hline 0 & null & no & no & yes \\
\hline 5 & P14 & yes & no & no \\
\hline 9 & P8 & yes & no & no \\
\hline 13 & empty & no & no & yes \\
\hline 17 & empy & no & no & yes \\
\hline 18 & empty & no & no & yes \\
\hline 25 & $5 \mathrm{SE}$ & yes & no & no \\
\hline Sajam & no & no & no & yes \\
\hline
\end{tabular}

Figure 3. Service email which would be sent for the technicians to alert about MERIEXWA work. 


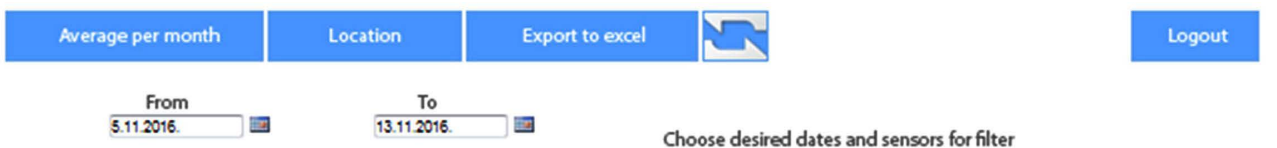

(a)
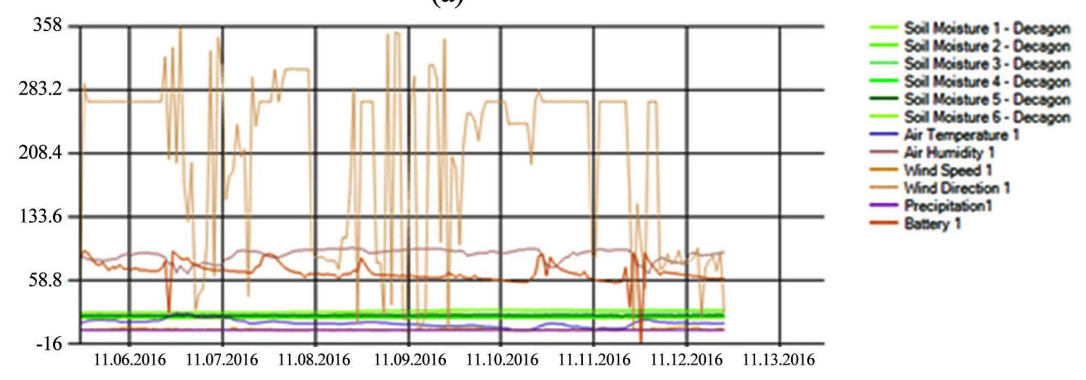

\begin{tabular}{|c|c|c|c|}
\hline Time & Device & ID & Value \\
\hline $12112016.9: 31: 47$ & 4 & $S M 1$ & 18.769 \\
\hline $12112016.931: 47$ & 4 & SN2 & 23.612 \\
\hline $1211.2016 .931: 47$ & 4 & SM3 & 21,185 \\
\hline $12112016.931: 47$ & 4 & SNA & 16,341 \\
\hline $12112016.931: 47$ & 4 & SM5 & 17,317 \\
\hline $12112016.931: 47$ & 4 & SMG & 13.926 \\
\hline $12112016.931: 47$ & 4 & BT1 & 60.964 \\
\hline $12112016.931: 47$ & 4 & AH1 & 92,000 \\
\hline $1211.2016 .931: 47$ & 4 & AT1 & 8,390 \\
\hline $1211.2016 .9: 31: 47$ & 4 & PP1 & 0,000 \\
\hline 12112016.931 .47 & 4 & WS1 & 0.810 \\
\hline $1211.2016 .931: 47$ & 4 & W01 & 21000 \\
\hline 12112016.83244 & 4 & SM1 & 18.281 \\
\hline 12112016.83224 & 4 & SM2 & 23,612 \\
\hline 12112016.83244 & 4 & SN3 & 20,697 \\
\hline 12112016.83244 & 4 & SNA & 16.341 \\
\hline 12112016.83244 & 4 & SM5 & 17,793 \\
\hline 12112016.82324 & 4 & SMG & 13,926 \\
\hline 12112016.83244 & 4 & вт1 & 60.964 \\
\hline 1211.2016 .83224 & 4 & AH1 & 91000 \\
\hline
\end{tabular}

(b)

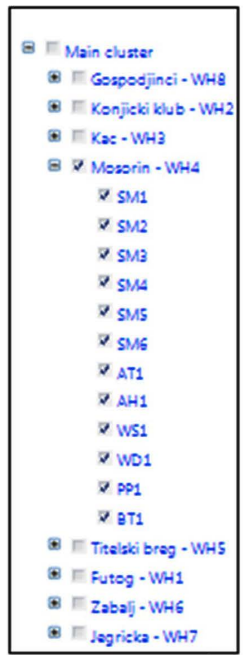

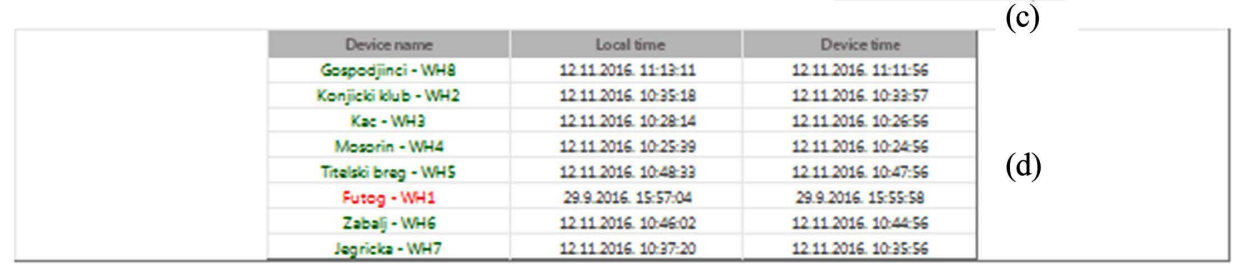

Figure 4. User portal; (a) graph producing measured data through time; (b) table with latest measured data per node; (c) selection of which data would be shown; (d) nodes time settings; Source: http://ftn.panonit.com:8095/login.aspx.

\subsection{NSUNET System—Network for Monitoring Urban Heat Island}

With the development of Internet, Internet of things and relevant information and communication technologies, the idea of smart planet was introduced [25]. Integrated part of each smart city are sensor networks used to collect real-time data such as temperature, humidity, wind direction, solar radiation and data related to atmospheric pollution. The most important task for such urban monitoring network (umn) is to build databases consisted of continuously measured data. Unfortunately, the most serious issues in umns are data losses caused primarily by communication problems between stations and servers (e.g., unreliable radio transmission, poor storage integrity of measured data, etc.).

The NSUNET stations placed inside Local Climate Zones (LCZ) [26] of Novi 
Sad (created through URBAN-PATH project, en.urban-path.hu), are equipped with ChipCap 2 sensors placed in radiation protection screens. Fully calibrated temperature and humidity sensors are sourced from the General Electric Measurement \& Control Company with the accuracy of the air temperature sensor of $\pm 0.3^{\circ} \mathrm{C}$, and that of the relative humidity sensor of $\pm 2 \%(20 \%-80 \% \mathrm{RH})$.

Only two stations have continuous power supply while other stations have electricity only when city lights are on (stations are placed on lampposts). During the day, i.e., when the city lights are off, the stations operate on an installed battery supply [19].

Data is stored in the station internal memory and sent to the Core Segment-methodology used in NSUNET topology which defines central location where data are being gathered, processed, validated and stored, in contrast to Remote Segment which represents area where stations are located.

Protocol used for data transmission is file transfer protocol (ftp). In order to increase data authenticity [27], each station is authenticated for ftp session by its unique username and password before it can start sending data. Each station has its id which is used to distinguish measured data.

Core Segment servers receive data as plain text files. Two locations are defined as primary and secondary-later is used in case of network failures. Both, stations and server track missing data (i.e. data that should have, but are not sent to Core Segment yet). In case of network failures stations have built-in algorithm when to begin re-transmitting data and to which location. Entire system can be configured and reconfigured either by direct access to stations in Remote Segment or remotely using configuration files stored on Core Segment.

Stations use coordinated universal time (utc) as the system time which is synchronized from the Core Segment (installed at the Faculty of Sciences, Novi Sad) using special configuration file named time.conf. Time used in NSUNET is represented as Unix time stamp (the number of seconds from the start of the Unix epoch-January 1, 1970).

Multiple algorithms are implemented on both sides (Remote and Core segment side) to track and alert about system work. Station monitors for sensor and modem errors, different connection problems, voltage and current failures and overall battery status, each represented through single bit in binary number. As result a decimal number is sent together with measured data which can be decoded to diagnose station work. If defined critical failures occur, station will send sms message to technicians. On the server side, data is analyzed and checked for validity, missing measurements are detected, received files are compressed and data are stored in mysql database server. Each process is followed by notify mechanism which is used to alert about system errors.

For visual system monitoring and work with data stored in database server, web application-NSUNET Portal-is developed (Figure 5). Different output types and formats can be selected to insure major compatibility with vastly used applications. 


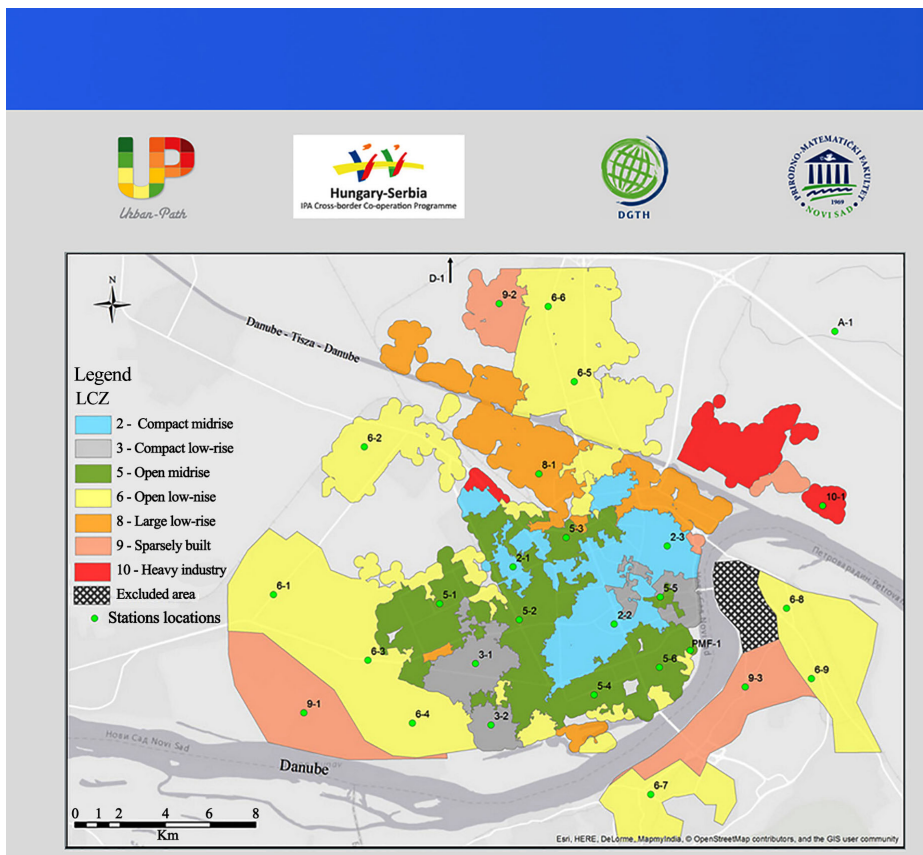

(a)
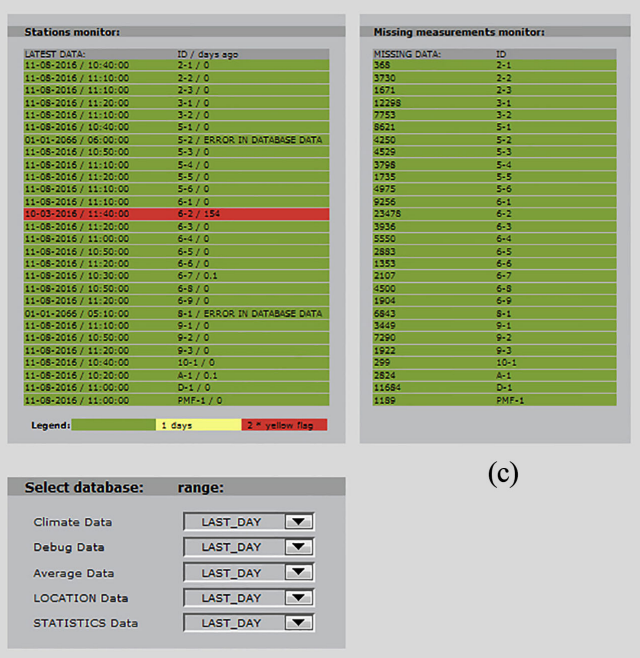

(c)

(b)

Figure 5. NSUNET-Portal; (a) map with location of stations; (b) database selection; (c) monitoring of latest data and data sanity check [19].

\section{Discussion}

The development of environmental monitoring systems requires a unique combination of technological and environmental understanding [28]. Different requirements introduce specific problems. To meet this challenge, environmental monitoring systems must be able to fulfill all demands. More important, it must be able to adapt for future demands. Without that attribute, system becomes rigid and often after certain period of time, it becomes unusable and obsolete [29].

This paper introduce proposition for new system, which is based on experience from three solutions presented in this paper and which is currently developed under laboratory conditions for new ipa project (Urban-prex project). The goal is to create affordable, reliable and robust, high-density sensors system with low percent of data loss. Such system should provide ground for scientific research together with ability to alert city emergency services to potential hazard.

\subsection{Selecting Proper Power Cells for Different Environment}

MERIEXWA system started around January 2014 and has been active for almost two years. Relative simplicity of its system design made it affordable. Locations where stations were required to measure inland excess water level don't provide any power supply. Only possible option is to rely on entire system power demands on batteries. In this scenario selecting reliable battery manufacturer and model is mandatory. Extreme weather conditions must be included for proper 
selection. Having this done, failure causes are decreased to minimum but still remain possible. This can be alleviated by introducing solar panel as secondary power supply and battery re-charger-at least during daytime. Either way, strong battery life monitoring mechanism must be implemented.

Although, some device manufacturers suggest battery replacement on a date stamp, proposed method can not be taken into account. Heavy usage or unfavorable environment conditions (e.g. temperature) can lead to battery failure before expected life-span is reached.

Lithium Thionyl Chlorides are primary cells with exceptionally low self-discharge rate of $0.08 \% /$ month. Wide operating temperature range from $-60^{\circ} \mathrm{C}$ to $+85^{\circ} \mathrm{C}$ makes them good selection for extreme environment conditions. Unfortunately, the electrolyte is toxic and reacts with water. Powering system which involves measuring water level from inside of the well, could lead to hazard [30].

NSUNET system use secondary cells as source of electricity which are recharged as long as lampposts are powered by city distribution. Selected batteries can power up remote station for more than a week without being recharged. Each station tracks information about minimal, average and maximal battery input/output for voltage and for current. Period without power supply is detected also and if it becomes longer then defined threshold, sms is sent to defined technicians as critical alert notification. At first glance, it looks like everything is taken into account considering properly powering NSUNET system. Unfortunately, data considering voltage, current and No Supply time (NSUNET variable used for tracking period without power supply), are stored inside Core Segment compressed archives but are never being analyzed at all. This feature is left for further implementations because it would present significant performance loss within system that is written as bash script. Excluding such analyze, current battery wear level cannot be determined, therefore, if battery become unreliable before it's predicted life-span, station will become unreliable during No Supply time period.

\subsection{Monitoring System Behavior}

MERIEXWA system monitoring is performed using service email which is sent to user on three-day basis containing information about stations which failed during their work within last ten days. As defined transmission interval is set to seven days, the fact remains that using this notification system, in the worst case scenario, information about failure is received after nine days. Furthermore, due to the gsm network problems station can fail to transmit data on seven days interval, even though it is fully operational. Usually, all data are received by server on next interval. Having all mentioned in mind, failures can be considered as critical only after fourteen days.

Station work conditions which can be expressed as only two states should be recorded using Status Value (sv). Each detected error is represented as unique 
bit set to 1 . This way if there are no errors detected, only one byte is transmitted to Core Segment (e.g. 0). Status Value is used in NSUNET system and proved to be reliable Remote Segment monitoring tool with minimal amount of transmitted data. NSUNET system implements this feature through NSUNET-Portal visual monitoring.

Full potential of such information is left unused. Automatic analyzing of sv could offer in detail statistics about system work. Such feature could upgrade system to be able to predict its work based on learned values. Currently this type of data is stored inside files received by system and not analyzed at all.

Monitoring data about remote stations only after they are received by server is not satisfactory solution. Errors defined as critical for each system could lead to the fact that server side is not fully aware about them (e.g. modem failures, critical power supply failures, sensor errors). Core Segment has information about failed transmission, but it cannot determine yet the nature of error. In case when gsm network is used for data transmission one additional mechanism is available for use. Station can send sms containing its critical condition status and alert immediately about it. NSUNET system uses this feature to alert technicians about such failures. At first this seems one step closer to less problems. Unfortunately, sms introduce additional costs in overall system work. Remote Segment stations in NSUNET system send sms on defined periods until failures are repaired. This for example, if lamppost is left without electricity for longer period (e.g. two weeks period in which time stations can be powered by installed batteries) could lead to undesired increase of overall system costs.

\subsection{Time Synchronization}

One of the most important challenges which must be solved concerning monitoring system work is time synchronization issues. The most common approach would be to use the network time protocol (ntp). Implementing such solution increase station code complexity and requires more hardware resources. Unless requirements demand different, less complexity equals more reliable system (e.g. less code, therefore less potential errors in it) [31].

To make them more affordable, stations used in NSUNET system has limited hardware resources which required different approach to the time synchronization. Special config file (time.conf) is used to solve time issues. With only 14 bytes per transmission, each station can check its current time against time given by Core Segment. Period between data transmission can be modified during system work to make it more adaptable for specific scenarios. As transmission period increase, system is more prone to time synchronization errors. When daylight changes occur, measurement is performed before next transmission will have inaccurate time. This problem is solved using utc which time modifications are small (26 leap seconds have been inserted since 1972). Nevertheless, the fact remains that some measurements can have inaccurate time.

WAHASTRAT system utilizes daylight saving in its work. Each time measurement is received by server, time correction is applied if there is need. Prob- 
lem with such approach is, when daylight savings occur, there is inevitable loss or overlapping of data.

\subsection{Communication between Segments}

Data structure and transport protocol used to send data through network differs from one implementation to another. Choosing right solution is based on goals which should be achieved.

MERIEXWA system utilize raw data structure transmitted using tcp protocol which minimize overall amount of transferred data between stations and server. Downside is that such approach requires specific custom developed server-side application to receive data sent from stations. Such solution usually becomes unusable over time because the companies that had developed it, are not employed for further development (e.g. not enough funds to support further development, companies cease to exist).

Data sent from station used in WAHASTRAT system, use http for its transmission. Such approach offers wider portability because it could be adapted to store data to web server, even though, WAHASTRAT relies on custom-built Java application, which makes it similar to MERIEXWA design. Using http which is run over tcp adds extra overhead to data transmission compared to MERIEXWA system data transmission.

NSUNET system is designed to be able to make data available to work with from the moment it arrives on Core Segment. It uses specific data structure stored in text files. With this approach data can be directly accessed using plain text editor. NSUNET use specific tool to analyze data, archive it and store into database server only to automate entire process and make work with measured data easier to end user. Cost paid for such solution is approximately $58 \%$ added overhead to network utilization. Even though average size of transmitted file is 256 bytes which is insignificant for today's network utilization, the fact remains that this approach adds significant amount of data to network transmission. As data transfer protocol, station use ftp to send data. Although this protocol is used mainly to transfer files over network, there is incompatibility between ftp clients and servers.

\subsection{Data Analyzes}

No matter what part of environment is monitored and what type of sensors are used in process, large time series of recorded data change our perspective and analyzes of surrounding area. It makes possible to detect rare and random events which are, if not impossible, than very hard to detect otherwise. Data combined from different environment monitoring systems help to draw conclusion about past actions as well as to predict future one.

In this paper, example of data collected between 2014-2017, from NSUNET stations placed within industrial zone in city of Novi Sad (Industrijska zona Jug), are used to assess the influence of urbanization on regional climate modification, which leads to the creation of urban climate. It can be noticed that on all time 
scales, industrial area is warmer that natural area with maximum difference of $1.8^{\circ} \mathrm{C}$ (difference in summer). Air temperature differences are smaller during winter and autumn with values of $1.1^{\circ} \mathrm{C}$ (Table 1$)$.

Contrary to air temperature, relative humidity in industrial area has smaller values than natural areas during all seasons and on annual level. The smallest differences occur during winter $(-3.7 \%)$, and they increase in spring leading to the maximum difference of $-11.4 \%$ in summer, after which they decrease to $-6.8 \%$ in autumn (Table 2 ).

According to results in the tables, we can generally conclude that urban landscape is characteristic with distinctly different structure, arrangement and composition of land cover than rural or natural landscape. A significant proportion of urban areas are covered with artificial-mostly impervious-surfaces, which substantially alter thermal regime of the landscape and thus modify climate of urban areas. Increased temperatures in urban areas might have significant impacts on many aspects including biodiversity [32] [33], population health [34] [35] [36] [37] and overall on sustainability of urban areas [38] [39]. Furthermore, the highest differences are occurred in night time, because of thermal capacity of artificial surface. It means that during the daytime the urban surface is heating by direct sun radiation (low albedo, about 15\%), and during the night time this surface release excess heat.

Table 1. Air temperature in industrial area of Novi Sad (Industrijska zona Jug) and in natural area outside of the city on annual and seasonal level in the period July 2014-June 2017.

\begin{tabular}{cccc}
\hline \multicolumn{3}{c}{ Meteorological stations } \\
\hline Air temperature $\left({ }^{\circ} \mathrm{C}\right)$ & Industrial area & Natural area & Industrial/natural differences \\
\hline Annual & 13.7 & 12.7 & 1.0 \\
Winter & 3.1 & 2.0 & 1.1 \\
Spring & 15.1 & 13.4 & 1.7 \\
Summer & 23.9 & 22.1 & 1.8 \\
Autumn & 13.3 & 12.2 & 1.1 \\
\hline
\end{tabular}

Table 2. Relative humidity in industrial area of Novi Sad (Industrijska zona Jug) and in natural area outside of the city on annual and seasonal level in the period July 2014-June 2017.

\begin{tabular}{cccc}
\hline \multicolumn{3}{c}{ Meteorological stations } \\
\hline Relative humidity (\%) & Industrial area & Natural area & Industrial/natural differences \\
\hline Annual & 75.4 & 82.9 & -7.5 \\
Winter & 87.4 & 91.1 & -3.7 \\
Spring & 66.6 & 75.4 & -8.8 \\
Summer & 67.0 & 78.4 & -11.4 \\
Autumn & 81.7 & 88.5 & -6.8 \\
\hline
\end{tabular}




\section{Conclusions}

Reliable system is not always proportional to complex one, and simplified one is not always the best approach. Having that in mind, together with acquired experience based on years of research and practical implementations, this paper offers guidelines for design of new system which is suitable for hydrology and climatology measurements. Beside different type of collected data, proposed system should offer early alert to possible environment hazard (that will be implemented in URBAN-PREX project; http://www.urban-prex.org/).

1) Monitoring network topology consists of Remote Segment, Core Segment and Third Party Segment (segment used for further data redistribution).

2) Measurements are stored inside station using erasable programmable read-only memory (eprom) which allows storing data for a minimal period of six months after which oldest data are replaced with current.

3) Open data structure is used. After measurement period is reached measured data are stored compatible for read in plain text editors. Backup algorithm is implemented to allow sending data to secondary server. Possibility for data to arrive on time is increased even if network failures occur, making system more responsive and reliable to deliver information as soon as it is measured. As transport device, gsm modem is used to send data using http protocol. Using proposed data structure transmission costs remains low.

4) Data are analyzed and compressed in Core Segment using NSUNET-sys_tool (NSUNET bash script used to automate process). To increase overall system performance apache web server module will be developed to replace NSUNET-sys_tool's the most time consuming parts, such as data parsing and analyzing segment. Such solution will allow for proposed system to increase overall amount of supported stations without investing in faster server hardware.

5) Station remote configuration is done using config files together with special time.conf file used as time synchronization, received during transmission. System time is defined as utc. Special config file variable will allow server to monitor for missing data and to request specific station to send all data stored inside its internal memory.

6) Critical conditions in Remote Segment are sent using sms notifications.

Proposed solution combines experience from three different systems developed and tested in last six years. Transmission costs remain low and affordable while using gsm (around 7MB per month per station), which allows greater area coverage. Increased possibility for measurement to arrive right on time, opens additional usage for the entire system. It can be used not only for scientific purposes, but also for example, to deliver information to wider public or city emergency services about current conditions. Future changes and improvements can be made inside different segments allowing system to remain operational for a long time.

\section{Acknowledgements}

This study is supported by following projects: Development of the excess inland 
water monitoring network, MERIEXWA project (no. HUSRB/1002/121/088), supported by the Hungarian-Serbian IPA Cross-border Co-operation Programme; Development of the water shortage hazard and adaptive water management strategies in the Hungarian-Serbian cross-border region, WAHASTRAT project (No. HUSRB/1203/121/130), supported by the Hungarian-Serbian IPA Cross-border Co-operation Programme; Development of the urban climate monitoring network in Novi Sad, URBAN-PATH project (No. HUSRB/1203/122/166), was partly supported by the Hungarian-Serbian IPA Cross-border Co-operation Programme; and Development of the monitoring, forecasting and development of online public early warning system for extreme precipitations and pluvial floods in urban areas in the Hungarian-Serbian cross-border region, Urban-prex project (No. HUSRB/1602/11/0097), is supported by the Hungarian-Serbian IPA Cross-border Co-operation Programme.

\section{Conflicts of Interest}

The authors declare no conflicts of interest regarding the publication of this paper.

\section{References}

[1] Mohd, F.O. and Shazali, K. (2012) Wireless Sensor Network Applications: A Study in Environment Monitoring System. Procedia Engineering, 41, 1204-1210. https://doi.org/10.1016/j.proeng.2012.07.302

[2] Paller, G., Szármes, P. and Élö, G. (2015) Power Consumption Considerations of GSM-Connected Sensors in the AgroDat.hu Sensor Network. Sensors \& Transducers, 189, 52-60.

[3] Kulkarni, K.A. and Zambare, M.S. (2018) The Impact Study of Houseplants in Purification of Environment Using Wireless Sensor Network. Wireless Sensor Network, 10, 59-69. https://doi.org/10.4236/wsn.2018.103003

[4] Mile, A., Okeyo, G. and Kibe, A. (2018) Hybrid IEEE 802.15.6 Wireless Body Area Networks Interference Mitigation Model for High Mobility Interference Scenarios. Wireless Engineering and Technology, 9, 34-48. https://doi.org/10.4236/wet.2018.92004

[5] Sharma, D., Verma, S. and Sharma K. (2013) Network Topologies in Wireless Sensor Networks: A Review. International Journal of Electronics \& Communication Technology, 4, 93-97.

[6] Lutakamale, A.S. and Kaijage, S. (2017) Wildfire Monitoring and Detection System Using Wireless Sensor Network: A Case Study of Tanzania. Wireless Sensor Network, 9, 274-289. https://doi.org/10.4236/wsn.2017.98015

[7] Horton, T., Bolt, M., Prather, C., Manobianco, J. and Adams, M.L. (2018) Airborne Sensor Network for Atmospheric Profiling. Wireless Sensor Network, 10, 93-101. https://doi.org/10.4236/wsn.2018.104005

[8] Delebarre, C., Pujolle, T., Cousin, G., Domon, A., Froux, J. and Jourdan, J. (2018) Wireless Low Cost $\mathrm{CO}_{2}$ Monitoring System Design and Evaluation Using Non Dispersive Infrared Sensor. Wireless Sensor Network, 10, 119-130. https://doi.org/10.4236/wsn.2018.106007

[9] Strobl, R.O. and Robillard, P.D. (2008) Network Design for Water Quality Moni- 
toring of Surface Freshwaters: A Review. Journal of Environmental Management, 87, 639-648.

[10] Gilbert, E.P.K., Kaliaperumal, B. and Rajsingh, E.B. (2012) Research Issues in Wireless Sensor Network Applications: A Survey. International Journal of Information and Electronics Engineering, 2, 702-706.

[11] Al-Subhi, T., Arafeh, B., Alzeidi, N., Day, K. and Touzene, A. (2018) A Void Avoidance Scheme for Grid-Based Multipath Routing in Under-Water Wireless Sensor Networks. Wireless Sensor Network, 10, 131-156. https://doi.org/10.4236/wsn.2018.107008

[12] Chapin, T.P., Todd, A.S. and Zeigler, M.P. (2014) Robust, Low-Cost Data Loggers for Stream Temperature, Flow Intermittency, and Relative Conductivity Monitoring. Water Resources Research, 50, 6542-6548. https://doi.org/10.1002/2013WR015158

[13] Abdullah, M.H., Ghani, S.A.C., Zaulkafilai, Z. and Tajuddin, S.N. (2017) Development Open Source Microcontroller Based Temperature Data Logger. 4th International Conference on Mechanical Engineering Research (ICMER 2017), 1-2 August 2017, 257. http://iopscience.iop.org/article/10.1088/1757-899X/257/1/012015/meta

[14] Ali, A.S., Zanzinger, Z., Debose, D. and Stephens, B. (2016) Open Source Building Science Sensors (OSBSS): A Low-Cost Arduino-Based Platform for Long-Term Indoor Environmental Data Collection. Building and Environment, 100, 114-126. https://doi.org/10.1016/j.buildenv.2016.02.010

[15] Payero, J.O., Nafchi, A.M., Davis, R. and Khalilian, A. (2017) An Arduino-Based Wireless Sensor Network for Soil Moisture Monitoring Using Decagon EC-5 Sensors. Open Journal of Soil Science, 7, Article ID: 79962.

[16] Lwin, K., Hashimoto, M. and Murayama, Y. (2014) Real-Time Geospatial Data Collection and Visualization with Smartphone. Journal of Geographic Information System, 6, Article ID: 44566.

[17] Kottek, M., Grieser, J., Beck, C., Rudolf, B. and Rubel, F. (2006) World Map of the Köppen-Geiger Climate Classification Updated. Meteorologische Zeitschrift, 15 , 259-263. https://doi.org/10.1127/0941-2948/2006/0130

[18] Jovanović, M., Pavić, D., Mesaroš, M., Stankov, U., Pantelić, M., Armenski, T., Dolinaj, D., Popov, S., Ćosić, Đ., Popović, L.J., Frank, A. and Crnojević, V. (2013) Water Shortage and Drought Monitoring in Bačka Region (Vojvodina, North Serbia)-Setting-Up Measurement Stations Network. Geographica Pannonica, 17, 114-124. https://doi.org/10.5937/GeoPan1304114J

[19] Šećerov, I., Savić, S., Milošević, D., Marković, V. and Bajšanski, I. (2015) Development of an Automated Urban Climate Monitoring System in Novi Sad (Serbia). Geographica Pannonica, 19, 174-183. https://doi.org/10.5937/GeoPan1504174S

[20] Gál, N. and Farsang, A. (2013) Weather Extremities and Soil Processes: Impact of Excess Water on Soil Structure in the Southern Great Hungarian Plain. In: Loczy, D., Ed., Geomorphological Impacts of Extreme Weather, Springer, Berlin, 313-325. https://doi.org/10.1007/978-94-007-6301-2_20

[21] Károly, B. (2013) Inland Excess Water. IPA Crossborder Cooperation Programme (HUSRB/1002/121/088).

[22] Brkić, M., Obradović, Đ., Dudarin, Z., Károly, B. and Živanov, M. (2013) Measurement and Monitoring System for Level of Groundwater. Key Engineering Materials, 543, 243-246. https://doi.org/10.4028/www.scientific.net/KEM.543.243

[23] Brkić, M., Dogan, V., Obradović, Đ. and Živanov, M. (2012) Hardware Realization 
of Measurement and Monitoring System for Level of Groundwater. Symposium Industrial Electronics INDEL, Banja Luka, 1-3 November 2012, 124-127. http://www.indel.etfbl.net/2014/resources/Proceedings_2012/INDEL_2012_Proceed ings.rar

[24] Reina, D.G., Toral, S.L., Barrero, F., Bessis, N. and Asimakopoulou, E. (2013) The Role of Ad Hoc Networks in the Internet of Things: A Case Scenario for Smart Environments. In: Bessis, N., Xhafa, F., Varvarigou, D., Hill, R. and Li, M., Eds., Internet of Things and Inter-Cooperative Computational Technologies for Collective Intelligence, Springer, Berlin, 89-113. https://doi.org/10.1007/978-3-642-34952-2_4

[25] Qiu, L., Liu, Z., Pereira, G.C.C.F. and Seo, H. (2017) Implementing RSA for Sensor nodes in Smart Cities. Personal and Ubiquitous Computing, 21, 807-813. https://doi.org/10.1007/s00779-017-1044-y

[26] Stewart, I.D. and Oke, T.R. (2012) Local Climate Zones for Urban Temperature Studies. Bulletin of the American Meteorological Society, 93, 1879-1900. https://doi.org/10.1175/BAMS-D-11-00019.1

[27] Kumari, S., Khan, M.K. and Atiquzzaman, M. (2015) User Authentication Schemes for Wireless Sensor Networks: A Review. Ad Hoc Networks, 27, 159-194. https://doi.org/10.1016/j.adhoc.2014.11.018

[28] Hart, J.K. and Martine, K. (2006) Environmental Sensor Networks: A Revolution in the Earth System Science? Earth-Science Reviews, 78, 177-191.

https://doi.org/10.1016/j.earscirev.2006.05.001

[29] Carlos-Mancilla, M., López-Mellado, E. and Siller, M. (2016) Wireless Sensor Networks Formation: Approaches and Techniques. Journal of Sensors, 2016, Article ID: 2081902.

[30] Lisbona, D. and Snee, T. (2011) A Review of Hazards Associated with Primary Lithium and Lithium-Ion Batteries. Process Safety and Environmental Protection, 89, 434-442. https://doi.org/10.1016/j.psep.2011.06.022

[31] Tashtoush, Y., Al-Maolegi, M. and Arkok, B. (2014) The Correlation among Software Complexity Metrics with Case Study. International Journal of Advanced Computer Research, 4, 414-419.

[32] Schmidt, K.J., Poppendieck, H.H. and Jensen, K. (2014) Effects of Urban Structure on Plant Species Richness in a Large European City. Urban Ecosystems, 17, 427-444. https://doi.org/10.1007/s11252-013-0319-y

[33] Čepelová, N., Kalusová, V. and Lososová, Z. (2017) Effects of Settlement Size, Urban Heat Island and Habitat Type on Urban Plant Biodiversity. Landscape and Urban Planning, 159, 15-22. https://doi.org/10.1016/j.landurbplan.2016.11.004

[34] Kovats, R.S. and Hajat, S. (2008) Heat Stress and Public Health: A Critical Review. Annual Review of Public Health, 29, 41-55. https://doi.org/10.1146/annurev.publhealth.29.020907.090843

[35] Tan, J., Zheng, Y., Tang, X., Guo, C., Li, L., Song, G., Zhen, X., Yuan, D., Kalkstein, A.J., Li, F. and Chen, H. (2010) The Urban Heat Island and Its Impact on Heat Waves and Human Health in Shanghai. International Journal of Biometeorology, 54, 75-84. https://doi.org/10.1007/s00484-009-0256-x

[36] Gabriel, K.M. and Endlicher, W.R. (2011) Urban and Rural Mortality Rates during Heat Waves in Berlin and Brandenburg, Germany. Environmental Pollution, 159, 2044-2050. https://doi.org/10.1016/j.envpol.2011.01.016

[37] Savić, S., Marković, V., Šećerov, I., Pavić, D., Arsenović, D., Milošević, D., Dolinaj, D., Nagy, I. and Pantelić, M. (2018) Heat Wave Risk Assessment and Mapping in 
Urban Areas: Case Study for a Midsized Central European City, Novi Sad (Serbia). Natural Hazards, 91, 891-911. https://doi.org/10.1007/s11069-017-3160-4

[38] Grimmond, C.S.B., Roth, M., Oke, T.R., Au, Y.C., Best, M., Betts, R., Carmichael, G., Cleugh, H., Dabberdt, W., Emmanuel, R., Freitas, E., Fortuniak, K., Hanna, S., Klein, L.S., Liu, C.H., Nickson, A., Pearlmutter, D., Sailor, D. and Voogt, J. (2010) Climate and More Sustainable Cities: Climate Information for Improved Planning and Management of Cities (Producers/Capabilities Perspective). Procedia Environmental Sciences, 1, 247-274. https://doi.org/10.1016/j.proenv.2010.09.016

[39] Huang, Q. and Lu, Y. (2018) Urban Heat Island Research from 1991 to 2015: A Bibliometric Analysis. Theoretical and Applied Climatology, 131, 1055-1068. https://doi.org/10.1007/s00704-016-2025-1 